\title{
EVALUASI PENGELOLAAN SEDIAAN FARMASI DAN BAHAN MEDIS HABIS PAKAI DI PUSKESMAS LANDASAN ULIN KOTA BANJARBARU
}

\author{
Amaliyah Wahyuni*, Saftia Aryzki, Ita Feteriah \\ Sekolah Tinggi Ilmu Kesehatan ISFI Banjarmasin \\ *: ameliakfar@gmail.com
}

\begin{abstract}
ABSTRAK
Pembangunan kesehatan adalah suatu upaya yang bertujuan untuk membangun kesadaran, kemauan dan kemampuan hidup bagi setiap orang agar dapat memperoleh derajat kesehatan yang setinggi tingginya. Pengelolaan sediaan farmasi dan bahan medis habis pakai melalui pelayanan kefarmasian di puskesmas meliputi beberapa kegiatan yaitu perencanaan, pengadaan, penerimaan, penyimpanan, pendistribusian, pemusnahan dan penarikan, pengendalian dan administrasi. Tujuannya adalah untuk menjamin ketersediaan dan keterjangkauan sediaan farmasi dan bahan medis habis pakai yang efisien, efektif dan rasional. Penelitian ini menggunakan metode deskriptif observatif. Populasi dan sampel adalah seluruh data pengelolaan obat yang mencakup perencanaan, permintaan, penerimaan, penyimpanan, pendistribusian, pemusnahan dan penarikan, pengendalian, dan administrasi Puskesmas Tahun 2019 dan 2020. Tempat dan waktu penelitian; tempat di Puskesmas Landasan Ulin Banjarbaru pada bulan Maret-April 2020. Data digunakan berupa lembar obsevasi dengan pengolahan data kesesuaiannya dengan SOP Kefarmasian dan Petunjuk Teknis Standar Pelayanan Kefarmasian di Puskesmas Kemenkes RI Tahun 2019 serta faktor yang mempengaruhi ketidaksesuaiannya Data dikumpulkan secara langsung menggunakan lembar observasi. Hasil penelitian menunjukkan kegiatan pengelolaan sediaan farmasi dan bahan medis habis pakai belum semuanya sesuai dengan pedoman yaitu SOP Kefarmasian di Puskesmas dan Petunjuk Teknis Standar Pelayanan Kefarmasian di Puskesmas Kemenkes RI Tahun 2019.
\end{abstract}

Kata Kunci: Sediaan Farmasi, Pengelolaan Obat, Puskesmas

\section{ABSTRACT}

Health development is an effort aimed to build awareness, willingness, and ability of life for everyone. The management of pharmaceutical preparations and medical materials through the pharmacy services in public health center includes several activities namely planning, procurement, acceptance, storage, distribution, destruction and withdrawal, control and administration. The goal is to ensure efficient, effective and rational availability and affordability of pharmaceutical preparations and medical materials. This research uses a descriptive observational method. Population and samples are all drug management data which includes planning, request, acceptance, storage, distribution, destruction and withdrawal, control, and administration of Puskesmas year 2019 and 2020. Place and time of research; Place in the 
Landasan Ulin public health center of Banjarbaru city of March-April 2020. Data is used in the form of obsevation sheet with data processing according to Kefarmasian SOP and technical guidance of standard Ministry of Pharmacy in Health care Department of Indonesia year 2019 as well as factors affecting its incompliance. This research uses a descriptive observational method. Population and samples are all drug management data which includes planning, request, acceptance, storage, distribution, destruction and withdrawal, control, and administration of public health center. Place in the public health center foundation of Ulin

Keywords: Pharmaceutical Preparations, Drug Management, Puskesmas

\section{PENDAHULUAN}

Salah satu upaya pemerintah untuk untuk menyelenggarakan pembangunan kesehatan di suatu wilayah adalah dengan mendirikan Rumah sakit dan Puskesmas, yang mana Puskesmas merupakan unit pelaksana tingkat pertama sebagai ujung tombak pembangunan kesehatan di Indonesia ${ }^{(2)}$.

Puskesmas merupakan fasilitas pelayanan kesehatan dasar yang menyelenggarakan upaya kesehatan pemeliharaan, peningkatan kesehatan (promotif), pencegahan penyakit (preventif), penyembuhan penyakit (kuratif), dan pemulihan kesehatan (rehabilitatif) yang dilakukan secara menyeluruh dan berkesinambungan ${ }^{(1)}$

Pelaksanaan upaya kesehatan merupakan satu kesatuan yang tidak dapat dipisahkan dari pelayanan kefarmasian di Puskesmas.

Pengelolaan sediaan farmasi dan bahan medis habis pakai melalui pelayanan kefarmasian di puskesmas meliputi beberapa kegiatan yaitu perencanaan, pengadaan, penerimaan, penyimpanan, pendistribusian, pemusnahan dan penarikan,pengendalian dan administrasi. Tujuannya adalah untuk menjamin ketersediaan dan keterjangkauan sediaan farmasi dan bahan medis habis pakai yang efisien, efektif dan rasional ${ }^{(4)}$

Pengelolaan sediaan farmasi dan bahan medis habis pakai dipuskesmas merupakan hal yang sangat penting dan perlu diperhatikan, karena pengelolaan yang tidak sesuai prosedur akan mengakibatkan pemakaian yang tidak tepat guna, akan banyak 
terdapat obat kadaluarsa serta tumpang tindih anggaran (2).

Penelitian ini dilakukan untuk meneliti, bagaimana pengelolaan sediaan farmasi dan bahan medis habis pakai di Puskesmas Landasan Ulin. Dan Apa saja faktor - faktor yang mempengaruhi ketidaksesuaian pada pengelolaan sediaan farmasi dan bahan medis habis pakai di Puskesmas Landasan Ulin.

\section{METODE PENELITIAN}

\section{Jenis Penelitian}

Jenis penelitian yang digunakan adalah penelitian non eksperimental yang bersifat deskriptif dengan menggunakan lembar observasi, dilakukan secara prosfektif dan retrospektif.

\section{Waktu dan Tempat Penelitian}

Penelitian akan dilaksanakan pada bulan Maret - April tahun 2020 di Puskesmas Landasan Ulin.

\section{Populasi dan Sampel}

Seluruh data pengelolaan obat yang mencakup perencanaan, permintaan, penerimaan, penyimpanan, pendistribusian, pemusnahan dan penarikan, pengendalian, dan administrasi di
Puskesmas Landasan Ulin Tahun 2019 dan Tahun 2020.

Teknik sampling yang digunakan pada penelitian ini adalah teknik sampling jenuh.

\section{Alat / Instrumen penelitian}

Alat dan Bahan yang digunakan pada penelitian ini adalah :

1. Chek list lembar observasi

2. Lembar wawancara

\section{Teknik Pengolahan data}

Dalam penelitian ini, pada lembar observasi akan diberi tanda cheklis sesuai hasil pengamatan, yaitu cheklis pada kolom sesuai atau pada kolom tidak sesuai, kemudian data dari hasil observasi tersebut akan dianalisis dan dicocokkan dengan data - data sekunder atau data pendukung dan diambil kesimpulan berupa deskripsi.

\section{HASIL DAN PEMBAHASAN}

\section{Perencanaan}

Perencanaan merupakan proses kegiatan seleksi obat dan bahan medis habis pakai untuk menentukan jenis dan jumlah obat dalam rangka pemenuhan kebutuhan Puskesmas, yang mana salah satu tujuannya adalah untuk 
meningkatkan efisiensi penggunaan obat $^{(3)}$.

Dari hasil penelitian menunjukkan bahwa dari masing masing 5 indikator perencanaan berdasarkan SOP Kefarmasian di Puskesmas dan Petunjuk Teknis Standar Pelayanan Kefarmasian di Puskesmas Kemenkes RI Tahun 2019 didapatkan hasil $100 \%$ sesuai.

\section{Pengadaan}

Tujuan dari pengadaan sediaan farmasi dan bahan medis habis pakai yaitu untuk memenuhi kebutuhan di puskesmas sesuai dengan perencanaan kebutuhan yang telah dibuat ${ }^{(3)}$.

Dua indikator pengadaan berdasarkan sop kefarmasian di puskesmas Landasan ulin 100\% sudah sesuai dengan hasil pengamatan pada saat penelitian dilakukan di Puskesmas landasan Ulin. Sama halnya dengan 6 indikator pengadaan berdasarkan Petunjuk teknis Standar Pelayanan Kefarmasian di Puskesmas Kemenkes RI tahun 2019, 100\% sudah sesuai dengan hasil pengamatan pada saat penelitian

\section{Penerimaan}

Penerimaan merupakan suatu kegiatan dalam menerima sediaan farmasi dan bahan medis habis pakai dari Instalasi farmasi kabupaten / Kota atau hasil pengadaan Puskesmas secara mandiri sesuai permintaan yang telah diajukan. Tujuannya agar sediaan farmasi yang diterima sesuai dengan kebutuhan berdasarkan permintaan yang diajukan Puskesmas dan memenuhi persyaratan keamanan, khasiat dan mutu ${ }^{(4)}$.

Dari 2 indikator penerimaan berdasarkan SOP kefarmasian di Puskesmas dan 3 indikator penerimaan berdasarkan Petunjuk Teknis standar Pelayanan kefarmasian di Puskesmas Kemenkes RI Tahun 2019, menunjukkan bahwa $100 \%$ indikator sesuai dengan hasil pengamatan pada saat penelitian.

\section{Penyimpanan}

Penyimpanan merupakan kegiatan pengaturan terhadap sediaan farmasi yang diterima agar aman, terhindar dari kerusakan fisik maupun kimia dan mutunya tetap terjamin sesuai dengan persyaratan yang ditetapkan ${ }^{(5)}$.

Dari $23 \quad$ Indikator 
penyimpanan berdasarkan SOP

Kefarmasian di Puskesmas, terdapat

4 indikator atau $17 \%$ yang tidak

sesuai dengan hasil pengamatan yaitu sudut lantai dan dinding yang tajam, pintu yang tidak dilengkapi kunci ganda, hanya terdapat satu kunci untuk pintu gudang Puskesmas yang mana hal ini disebabkan oleh kondisi bangunan dari Puskesmas itu sendiri.

Selain itu, penyusunan obat tidak berdasarkan alphabet karena setiap obat memiliki jumlah yang berbeda yang mana obat yang termasuk cepat pergerakannya (fast moving) biasanya jumlahnya lebih banyak dibandingkan dengan stok obat yang lambat pergerakannya (slow moving), sehingga rak dan lemari didalam gudang obat tidak memiliki ruang yang cukup.

\section{Pendistribusian}

Tujuan

pendistribusian adalah memenuhi kebutuhan sediaan farmasi dan bahan medis habis pakai kepada sub unit pelayanan kesehatan yang ada diwilayah kerja puskesmasdengan jenis, mutu, jumlah dan waktu yang tepat ${ }^{(3)}$.

Dari 4 indikator pendistribusian berdasarkan SOP

Kefarmasian di Puskesmas, 100\% menunjukkan hasil yang sesuai dengan pengamatan. Selain didistribusikan ke unit pelayanan di Puskesmas, obat juga didistribusikan kepada unit pelayanan luar gedung seperti pustu, poskeskel dan pusling. Dalam setiap distribusi harus disertai dengan dokumen kelengkapan agar tertib administrasi.

\section{Pemusnahan dan Penarikan}

Pemusnahan dilakukan pada sediaan farmasi dan Bahan Medis Habis Pakai apabila produk tidak memenuhi mutu, kadaluarsa, ataupun dicabut izinedarnya ${ }^{(4)}$.

Dari 4 indikator pemusnahan dan penarikan berdasarkan SOP Kefarmasian di Puskesmasterdapat 1 indikator yang tidak sesuai, yaitu tidak adanya catatan nama, jumlah dan tanggal kadaluarsa di buku pencatatan obat rusak / kadaluarsa, hal ini dikarenakan untuk catatan nama, jumlah dan tanggal kadaluarsa obat yang akan ditarik dan dimusnahkan tidak menggunakan buku pencatatan obat kadaluarsa atau rusak, tetapi menggunakan form laporan obat rusak dan kadaluarsa. 


\section{Pengendalian}

Pengendalian sediaan farmasi dan bahan medis habis pakai merupakan suatu kegiatan untuk memastikan tercapainya sasaran yang diinginkan sesuai dengan strategi dan program yang telah ditetapkan sehingga tidak terjadi kekuranagn atau kelebihan obat di Puskesmas ${ }^{(6)}$.

Dari 5 indikator pengendalian berdasarkan SOP Kefarmasian di Puskesmas, 100 persen sesuai dengan hasil pengamatan dan wawancara yang dilakukan pada saat penelitian. Pada proses pengendalian setiap pemakaian rata - rata perbulan harus dihitung, dan juga harus menentukan stok optimum, stok pengaman, waktu tunggu agar tidak terjadi kekosongan obat. Sedangkan dari 14 indikator pengendalian berdasarkan Petunjuk Teknis Standar Pelayanan Kefarmasian di Puskesmas Kemenkes RI tahun 2019, ada 5 indikator yang tidak sesuai atau sekitar $36 \%$.

\section{Administrasi}

Administrasi terdiri dari
pencatatan dan pelaporan yang

bertujuan untuk melakukan pengendalian dan pengaturan sediaan farmasi dan bahan medis habis pakai di Puskesmas, serta sumber data untuk pembuatan laporan Puskesmas (7).

Dari 5 indikator administrasi berdasarkan SOP Kefarmasian di Puskesmas, didapatkan 4 indikator atau $80 \%$ hasil yang sesuai, sedangkan 1 indikator atau 20\%

tidak sesuai yang mana untuk obat yang rusak / kadaluarsa tidak dicatat didalam buku pencatatan, tetapi hanya menggunakan form laporan obat rusak atau kadaluarsa, hal ini disebabkan agar pendataan lebih efisien. Administrasi sangat penting dalam pengelolaan obat di Puskesmas yang bertujuan untuk pedoman perencanaan dan pengadaan untuk memenuhi kebutuhan obat di Puskesmas.

Berdasarkan Petunjuk Teknis Standar Pelayanan Kefarmasian di Puskesmas Kemenkes RI tahun 2019, dari 8 indikator kegiatan administrasi, ada 5 indikator atau $63 \%$ yang sesuai. 
Tabel 1. Jumlah Persentase Kesesuaian Pengelolaan Sediaan Farmasi Dan BahanMedis Habis Pakai Di Puskesmas Landasan Ulin

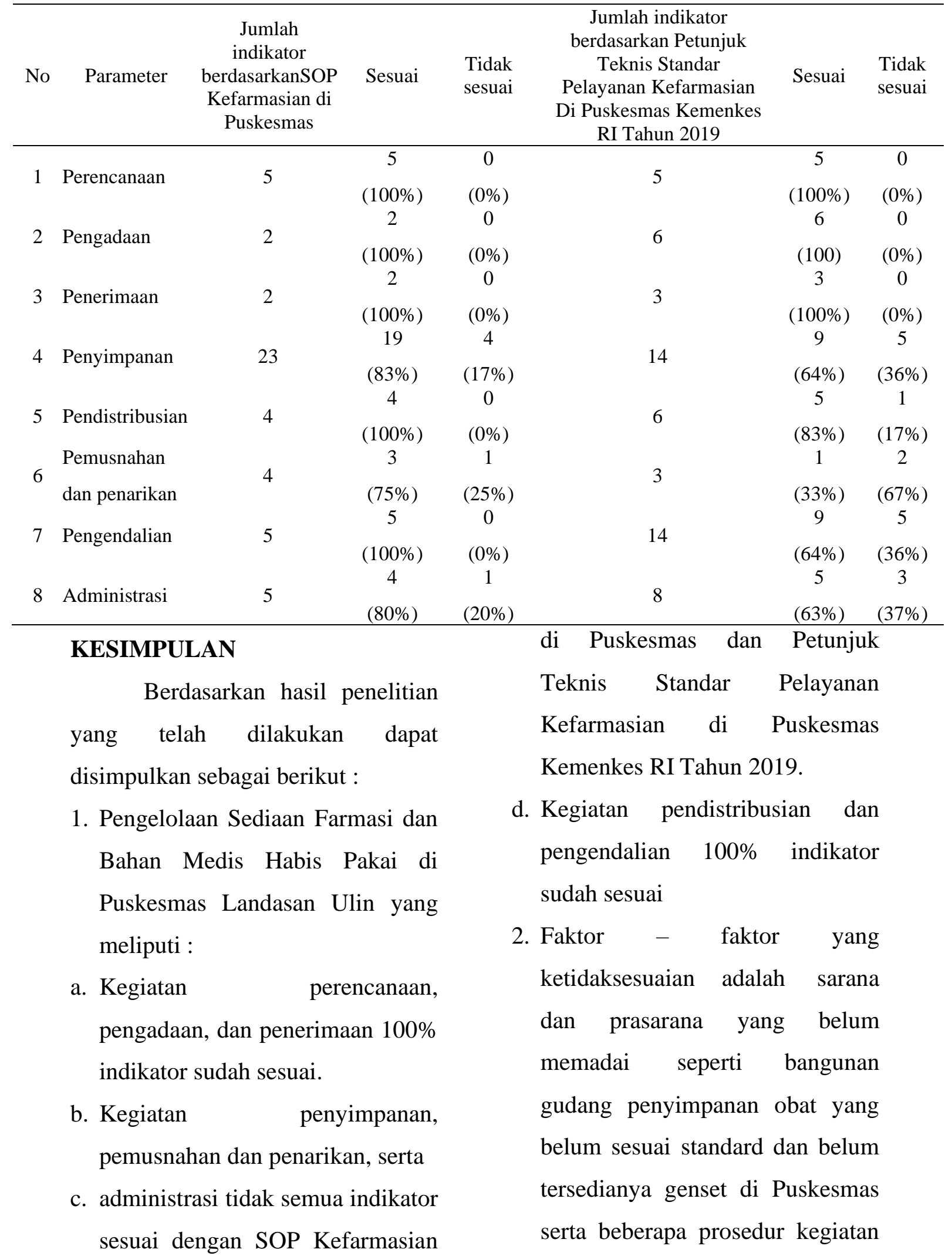




$$
\begin{array}{lrr}
\text { pengendalian, } & \text { pemusnahan dan } \\
\text { penarikan yang } & \text { belum } \\
\text { terkoordinasi } & \text { secara } & \text { maksimal } \\
\text { dengan Dinas } & \text { Kesehatan } \\
\text { Kabupaten / Kota. } &
\end{array}
$$

\section{UCAPAN TERIMA KASIH}

Terimakasih sebesarbesarnya pada pimpinan STIKES ISFI Banjarmasin yang mendukung peneliti untuk menyelesaikan penelitian ini. Dan Puskesmas Landasan Ulin kota Banjarbaru yang telah memberikan kesempatan untuk pengambilan penelitian.

\section{DAFTAR PUSTAKA}

1. Kementerian Kesehatan, 2014, Peraturan Menteri Kesehatan Republik Indonesia Nomor 75 Tahun 2014 Tentang Pusat Kesehatan Masyarakat, Jakarta, Kementerian Kesehatan Republik Indonesia.

2. Al - Hijrah, Muh.,dkk. (2013) Studi tentang pengelolaan obat di Puskesmas Madani Kabupaten Moras tahun 2013.

3. Chaira, dkk (2016) "Evaluasi Pengelolaan Obat pada Puskesmas di Kota Pariaman" Jurnal sains farmasi dan klinis, 3 (1), 35-41

4. Dirjen Binfar,2010 (2010) "Materi Pelatihan Manajemen Kefarmasian di Instalasi Farmasi Kabupaten/Kota Direktorat Bina Publik dan Perbekalan
Kesehatan Direktorat Jenderal Bina Kefarmasian dan Alat Kesehatan Kementerian Kesehatan RI".

5. Kementerian Kesehatan, 2019, Petunjuk Teknis Standar Pelayanan Kefarmasian di Puskesmas, Jakarta, Kementerian Kesehatan Republik Indonesia.

6. Kementerian Kesehatan, 2016, Peraturan Menteri Kesehatan Republik Indonesia Nomor 74 Tahun 2016 Tentang Standar Pelayanan Kefarmasian di Puskesmas, Jakarta, Kementerian Kesehatan Republik Indonesia.

7. Wahyuni, Amaliyah, 2018, Evaluasi Penyimpanan Sediaan Farmasi di Gudang Puskesmas se kota Banjarmasin, Jurnal Insan Farmasi Indonesia Vol.1 No 1, 166-174 